\title{
EFFECT OF SEED QUALITY STIMULATION IN KHAO DAWK MALI 105 PADDY DURING THE DORMANCY PERIOD USING INFRARED RADIATION
}

\author{
CHANAT VIPATTANAPORN ${ }^{1}$, CHERDPONG CHIAWCHANWATTANA ${ }^{2}$, JUCKAMAS \\ LAOHAVANICH $^{1}$, PHIRAYOT KHAENGKAN ${ }^{3}$ AND SUPHAN YANGYUEN*1
}

${ }^{1}$ Mechanical Engineering, Faculty of Engineering, Mahasarakham University, Maha Sarakham 44150, Thailand. ${ }^{2}$ Farm Mechanics Program, Department of Technical Education in Mechanical Engineering, Faculty of Technical Education, Rajamangala University of Technology Isan Khonkaen campus, Khonkaen 40000, Thailand. ${ }^{3}$ Department of Agricultural Technology, Faculty of Technology, Mahasarakham University, Maha Sarakham 44150, Thailand.

*Corresponding author: suphan.y@msu.ac.th

Submitted final draft: 16 October $2020 \quad$ Accepted: 27 November $2020 \quad$ http://doi.org/10.46754/jssm.2021.02.018

\begin{abstract}
Studies and developments related to increasing the nutritional value of rice have been receiving widespread attention. One of the most popular techniques for increasing the nutritional value of rice during processing is germination. This study aims to break the dormancy of rough rice (Oryza sativa L.), cultivar Khao Dawk Mali 105 (KDML105), by using infrared radiation to stimulate seed quality (seed vigour and seed germination were included in this study). This study used a full factorial in a completely randomized design (CRD) with stimulation by different factors, including storage periods of 3, 5, 7 and 9 weeks; infrared wavelengths of $4.00,3.75$ and $3.52 \mu \mathrm{m}$; and duty cycles of radiation of 1,2 and 3 cycles. The feed rate was controlled at $20 \mathrm{~kg} \cdot \mathrm{hr}^{-1}$, and the seed moisture content did not exceed $14 \% \mathrm{wb}$. It was found that the storage period, infrared wavelength, and duty cycle of radiation significantly affect the seed quality at $\mathrm{P} \leq 0.05$. For good performance, we recommend a storage period of 5 weeks, an infrared wavelength of $3.75 \mu \mathrm{m}$ and a duty cycle of 2 cycles.
\end{abstract}

Keywords: Seed dormancy, GABA, infrared ray, Seed vigour, Seed germination Abbreviations: [KDML105, SP].

\section{Introduction}

Nowadays, awareness of healthcare is a priority and of wide interest. An important factor in this is the selection of a healthy diet. Rice (Oryza sativa L.), which is the staple food of much of the world population, has been studied and developed continuously to increase its nutritional value (Fresco, 1947). This includes techniques for rice processing that are currently gaining a lot of research interest, such as "germinated brown rice" (GBR), which is rich in nutrients and salutary vitamins (Das, Gupta, Kapoor, Banerjee, \& Bal, 2008; Srisang, Varanyanond, Soponronnarit, \& Prachayawarakorn, 2011; Cho \& Lim, 2016), such as the important substance $\gamma$-aminobutyric acid (GABA), which is beneficial to the nervous system and brain activity (Thongekkaew, 2015), and total phenolic compounds with antioxidant properties (Antioxidant), etc. "germinated rough rice" (GRR), also known as parboiled rice (Chaiyachet, 2016). From the research, it is found that germinated rough rice has a higher amount of important substances compared with germinated brown rice (Moongngarm \& Saetung, 2010). However, post-harvesting of the Khao Dawk Mali 105 (KDML 105) rice varieties (which is another popular species in Thailand) will have a seed dormancy period for 8 weeks, so it cannot be germinated immediately as it has to pass the drying process. The paddy has to be dried to $14 \% \mathrm{wb}$ and stored for $12-32$ weeks before germination so that the required high seed germination can be achieved (National Bureau of Agricultural Commodity and Food Standards, 2012a; 2012b).

The objective of this research was to examine the effect of seed quality stimulation conditions on seed vigour and germination of Khao Dawk Mali 105 paddy and to break its dormancy using infrared radiation. This is so that the agricultural industry can have the opportunity to increase its production capacity, and to provide knowledge 
for the development of innovative rice products that will be recognized as a valuable food that possesses high nutritional benefits for human health.

\section{Materials and Methods}

\section{Rice Samples}

Rough rice of Oryza sativa L., cultivar KDML 105 (a popular jasmine rice cultivar for planting in the Northeast of Thailand), was selected for the study, and it was obtained from a single planting area in Mahasarakham Province, Thailand. To prepare the germinated rice samples, after harvesting, the rice was kneaded, the moisture reduced to $14 \% \mathrm{wb}$, and impurities and invalid seeds were separated out according to the seed quality inspection standard (ISTA, 1981; AOSA, 1983; Duangpatra, 1986).

(A)

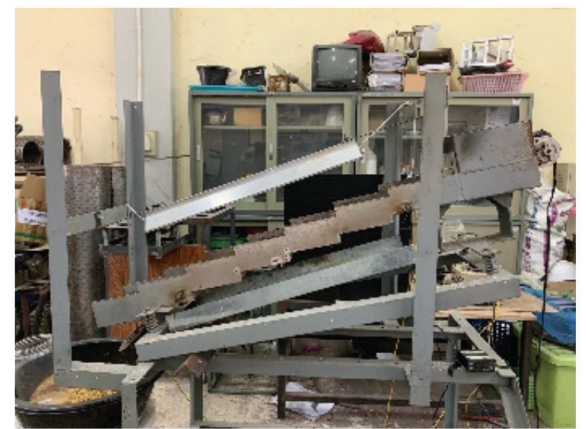

\section{Infrared Radiation Unit}

The infrared radiation unit had a rectangular trough of $0.15 \times 1 \mathrm{~m}$, and a horizontal angle of 11 degrees with a level of $0.01 \mathrm{~m}$ in every 0.1 m step. A $0.5 \mathrm{HP}$ vibrating motor was installed to ensure that the paddy turns over consistently under the infrared radiation. A near-infrared radiation generator equipped with tungsten incandescent lamps of 1,000 W (Figure 1 (A)) was installed at a distance of $0.2 \mathrm{~m}$ from the rails to allow effective radiation and heat transmission to the surface (Laohavanich, 2008) (Figure 1 (B)). The wavelength could be adjusted with a Stendal voltage regulator as shown in Figure 1 (C).

\section{Experimental Design and Testing Methods}

A $4 \times 3 \times 3 \times 3$ full factorial in a completely randomized design (CRD) was used to study the conditions of seed quality stimulation by means

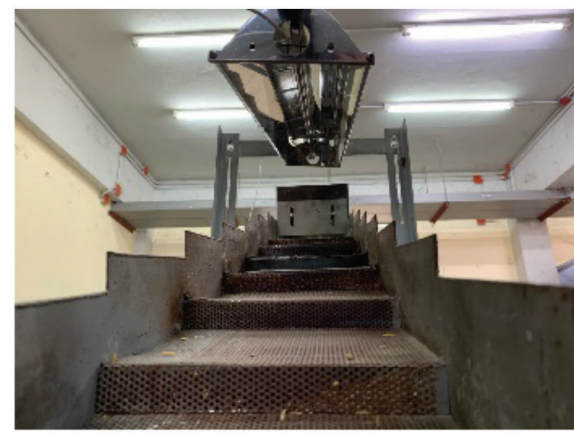

(B)

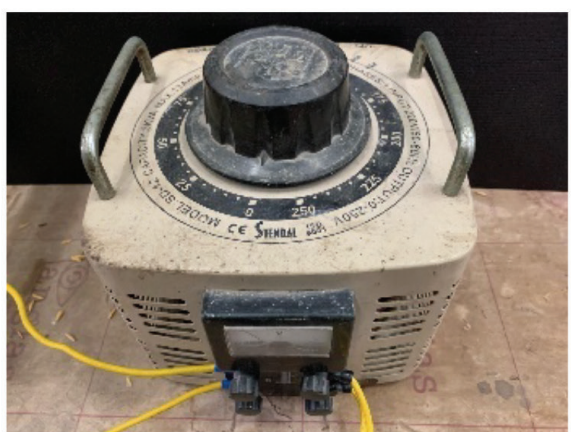

(C)

Figure 1: The infrared radiation unit (A), near-infrared radiation generator with tungsten incandescent lamps of $1,000 \mathrm{~W}(\mathrm{~B})$ and voltage regulator $(\mathrm{C})$ 
of infrared radiation at each level of the factors that affect the two values of seed vigour and germination.

The study used paddy that was stored in accordance with the quality inspection standard at four different storage periods of 3, 5, 7 and 9 weeks. The feed rate was constant at 20 $\mathrm{kg} \cdot \mathrm{hr}^{-1}$. The paddy was stimulated using infrared radiation. Three levels of infrared wavelengths were used in the experiment: 4.00, 3.75 and $3.52 \mu \mathrm{m}$. The temperature at the surface of the infrared generator was 450,500 and $550^{\circ} \mathrm{C}$, respectively. The infrared stimulation used in the study was varied between the first, second and third cycles, and each experiment was repeated three times. When the paddy was stimulated by infrared radiation, the seeds subjected to the different levels of each factor were germinated using the between-paper method and seed counting trays, and then kept in a clear plastic box at normal room temperature (Figure 2).
The boxes were opened for a first count on the fifth day after germination to record the seed vigour percentage. They were opened again for a final count 14 days after germination to record the seed germination percentage. All recorded values were examined for the maximum acceptable difference in seed germination tests (ISTA, 1981; AOSA, 1983; Duangpatra, 1986).

\section{Statistical Analysis and Model Development}

Data were expressed as mean $\pm \mathrm{SD}$, in triplicate. The data obtained from the measurements were subjected to univariate analysis of variance and least significant difference (LSD) tests to determine the significant differences between the samples in terms of seed quality (seed vigour and germination). The variation was analysed using a statistical program at a significance level of $\mathrm{P} \leq 0.05$. The method used results from the observed parameters from the experiment and an analysis of regression selected from $\mathrm{R}^{2}$.
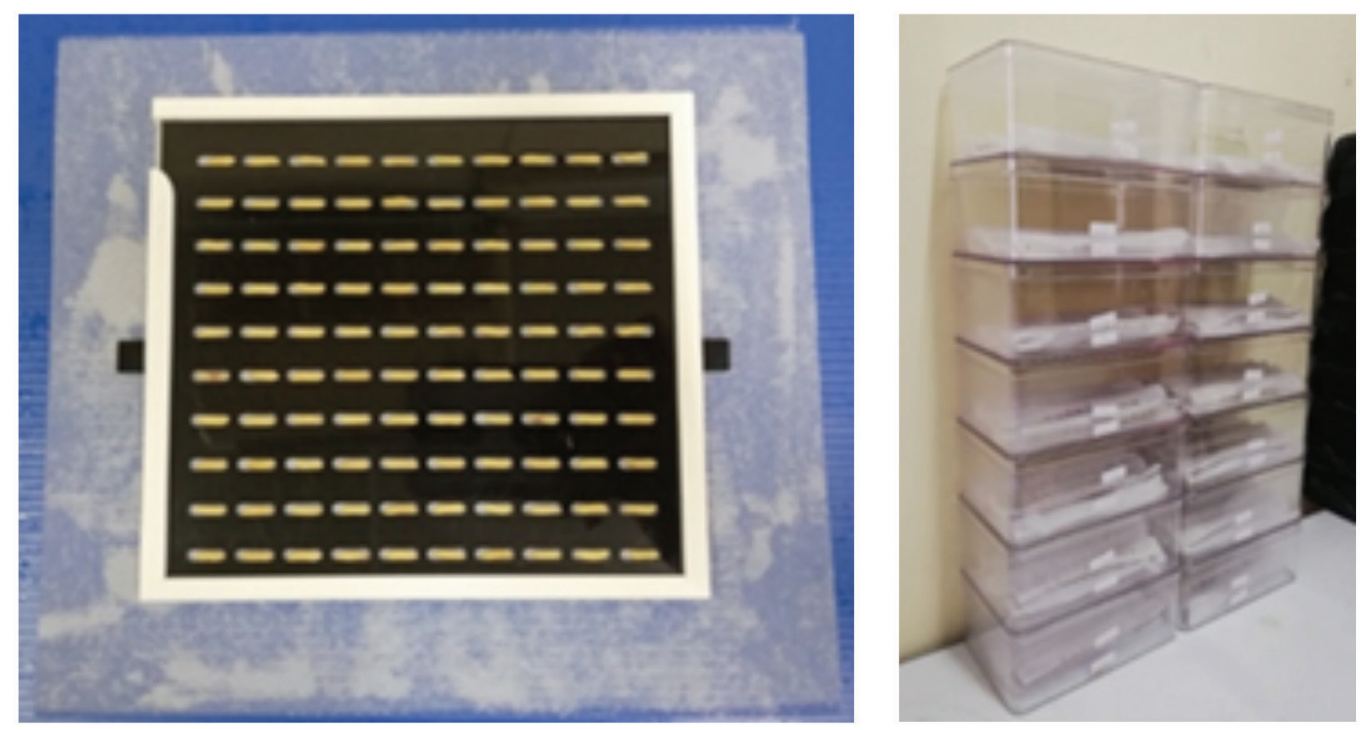

Figure 2: Seed counting tray and clear plastic storage box 


\section{Results and Discussion}

\section{Effect of Storage Period on Seed Quality}

The effect of the conditions used to stimulate the quality of this paddy was tested to determine the seed vigour and germination values according to the storage periods of 3, 5, 7 and 9 weeks, and it was found that that the average percentages of seed vigour were 37.67-99.67 and the average percentages of seed germination were 45.67-99.67, respectively, as shown in Table 1.
From Table 2, the statistical variation was analyzed. It was found that the storage period had a highly significant effect on the seed quality at the confidence level of 0.01 . This result is consistent with the findings of other researchers (Maisont \& Narkrugsa, 2010; Roohinejad et al., 2011; Prakhethanang, Chiawchanwattana et al., 2019), who explained that the storage period affected the quality of the seeds in terms of both seed vigour and germination.

From Table 1, a correlation graph was

Table 1: The effect of storage period (weeks) on seed quality

\begin{tabular}{ccc}
\hline $\begin{array}{c}\text { Storage period } \\
\text { (weeks) }\end{array}$ & $\begin{array}{c}\text { Vigour } \\
\mathbf{( \% )}\end{array}$ & $\begin{array}{c}\text { Germination } \\
(\%)\end{array}$ \\
\hline 3 & $37.67 \pm 5.51$ & $45.67 \pm 5.69$ \\
5 & $87.67 \pm 1.15$ & $90.00 \pm 1.73$ \\
7 & $99.67 \pm 0.58$ & $99.67 \pm 0.58$ \\
9 & $98.33 \pm 0.58$ & $99.00 \pm 1.00$ \\
\hline
\end{tabular}

Table 2: The statistical analysis with ANOVA of the effect of storage period (weeks) on seed quality

\begin{tabular}{ccccc}
\hline Indicators & df & MS & F-value & P-value \\
\hline Vigour & 3 & 33078.0 & 3536.02 & $0.00^{* *}$ \\
Germ & 3 & 28084.7 & 3811.27 & $0.00^{* *}$ \\
\hline
\end{tabular}

**Significant at $\mathrm{P} \leq 0.01$

constructed to show the storage period and levels of seed vigour and germination (Figure 3). It was found that as the storage period increased, the level of seed vigour and germination increased. A longer storage period resulted in a greater

Seed vigour $=-3.2083 \mathrm{x}^{2}+48.2 \mathrm{x}-76.825$

Seed germination $=-2.8125 \mathrm{x}^{2}+42.233 \mathrm{x}-54.504$ impact on seed quality. This agrees with Maisont and Narkrugsa (2010), Roohinejad et al. (2011), and Prakhethanang et al. (2019), and can be written as Equations (1) and (2), respectively. 




$\cdots \leftrightarrow$ VIGOR $\longrightarrow$ GERM

Figure 3: The correlation between storage period and amount of seed vigour and germination

Effect of Infrared Radiation and Radiation Cycle on Seed Quality for Each Storage

\section{Period}

From the above study, it was found that the storage period affected the quality of the grain. Therefore, a further study was carried out on the effect of seed quality stimulation using infrared rays at each factor level and for each storage period.

The data from Table 3 were used for an ANOVA with a LSD test to analyse the statistical variation. It was found that when compared with the average reference values of seed vigour and germination, the values at the storage period of 5 weeks with an infrared wavelength of $3.75 \mu \mathrm{m}$ and two cycles of infrared radiation were higher by $6.7 \%$ and $5.3 \%$, respectively (at $\mathrm{P} \leq 0.05$ ), and when measuring the temperature of the rice seeds, the above factors were found to have a temperature of $49.43^{\circ} \mathrm{C}$. This result is consistent with Prakhethanang et al. (2019), who explained that the appropriate temperature could stimulate the seed quality in terms of both seed vigour and germination. However, regarding stimulation with infrared radiation, samples stored for 7 and 9 weeks showed insignificant differences from the reference value (because this cultivar of rice has a dormancy period of 8 weeks; therefore values at 7 and 9 weeks were not statistically different), and those stored for 3 weeks also had significantly lower values, as shown in Table 3.

From the results of the correlation between the factors and responses, it was found that the seed vigour and germination values are highly positive. As for the relationship between seed vigour and germination and the storage period (SP), it can be explained that when the storage period increases, the seed vigour and seed germination values tend to increase accordingly. At various wavelengths and numbers of stimulation cycles, it can be explained that with the decrease of the infrared wavelength and increase of the number of stimulation cycles, the seed vigour and germination tend to decrease. This result is consistent with Maisont and Narkrugsa (2010) and Roohinejad et al. (2011), who explained that the storage period affected the seed vigour and germination. Moreover, stimulation with too much infrared radiation causes the rice temperature to be too high and will affect the quality (Prakhethanang et al., 2019), as shown in Table 4. 
Table 3: The effect of infrared radiation and radiation cycles on seed quality for each storage period

\begin{tabular}{|c|c|c|c|c|c|c|c|c|c|}
\hline \multirow{2}{*}{$\begin{array}{c}\lambda \mathrm{IR} \\
(\mu \mathrm{m})\end{array}$} & \multirow[t]{2}{*}{ Cycle } & \multicolumn{4}{|c|}{ Vigour (\%) } & \multicolumn{4}{|c|}{ Germination (\%) } \\
\hline & & 3WAS & 5WAS & 7WAS & 9WAS & 3WAS & 5WAS & 7WAS & 9WAS \\
\hline \multicolumn{2}{|c|}{ Ref, value } & $37.67^{\text {fgh }}$ & $87.67^{\mathrm{de}}$ & $99.67^{\mathrm{a}}$ & $98.33^{\mathrm{a}}$ & $45.67^{\mathrm{HI}}$ & $90.00^{\mathrm{EFG}}$ & $99.67^{\mathrm{AB}}$ & $99.00^{\mathrm{AB}}$ \\
\hline & 1 & $36.33^{\mathrm{ghi}}$ & $89.00^{\mathrm{de}}$ & $97.00^{\mathrm{ab}}$ & $99.00^{\mathrm{ab}}$ & $39.00^{\mathrm{J}}$ & $92.33^{\mathrm{DEF}}$ & $98.33^{\mathrm{AB}}$ & $99.00^{\mathrm{AB}}$ \\
\hline \multirow[t]{3}{*}{4.00} & 2 & $39.33^{\mathrm{fg}}$ & $87.33^{\mathrm{de}}$ & $99.67^{\mathrm{ab}}$ & $99.67^{\mathrm{ab}}$ & $46.33^{\mathrm{H}}$ & $89.00^{\mathrm{EFG}}$ & $99.67^{\mathrm{AB}}$ & $99.67^{\mathrm{AB}}$ \\
\hline & 3 & $31.33^{\mathrm{jk}}$ & $89.00^{\mathrm{de}}$ & $99.33^{\mathrm{a}}$ & $99.00^{\mathrm{ab}}$ & $38.67^{\mathrm{J}}$ & $91.00^{\mathrm{DEF}}$ & $99.67^{\mathrm{AB}}$ & $99.00^{\mathrm{AB}}$ \\
\hline & 1 & $41.33^{\mathrm{f}}$ & $89.33^{\mathrm{de}}$ & $96.33^{\mathrm{abc}}$ & $99.00^{\mathrm{ab}}$ & $41.67^{\mathrm{IJ}}$ & $91.67^{\mathrm{DEF}}$ & $97.33^{\mathrm{ABC}}$ & $99.33^{\mathrm{AB}}$ \\
\hline \multirow[t]{3}{*}{3.75} & 2 & $32.33^{\mathrm{ijk}}$ & $94.33^{\mathrm{bc}}$ & $97.67^{\mathrm{ab}}$ & $98.00^{\mathrm{ab}}$ & $37.67^{\mathrm{JK}}$ & $95.33^{\mathrm{BCD}}$ & $98.67^{\mathrm{AB}}$ & $98.33^{\mathrm{AB}}$ \\
\hline & 3 & $35.67^{\mathrm{ghij}}$ & $89.00^{\mathrm{de}}$ & $96.67^{\mathrm{ab}}$ & $99.00^{\mathrm{ab}}$ & $33.33^{\mathrm{K}}$ & $91.00^{\mathrm{DEF}}$ & $97.67^{\mathrm{ABC}}$ & $99.33^{\mathrm{AB}}$ \\
\hline & 1 & $32.33^{\mathrm{ijk}}$ & $87.00^{\mathrm{de}}$ & $96.00^{\mathrm{abc}}$ & $99.67^{\mathrm{ab}}$ & $37.67^{\mathrm{JK}}$ & $88.00^{\mathrm{FG}}$ & $97.67^{\mathrm{ABC}}$ & $100^{\mathrm{A}}$ \\
\hline \multirow[t]{4}{*}{3.52} & 2 & $34.33^{\mathrm{hij}}$ & $91.67^{\mathrm{cd}}$ & $98.67^{\mathrm{ab}}$ & $97.67^{\mathrm{ab}}$ & $40.00^{\mathrm{J}}$ & $93.33^{\mathrm{CDE}}$ & $99.33^{\mathrm{AB}}$ & $98.00^{\mathrm{AB}}$ \\
\hline & 3 & $28.33^{\mathrm{k}}$ & $84.67^{\mathrm{e}}$ & $97.67^{\mathrm{ab}}$ & $99.00^{\mathrm{ab}}$ & $40.33^{\mathrm{J}}$ & $86.00^{\mathrm{G}}$ & $99.67^{\mathrm{AB}}$ & $99.33^{\mathrm{AB}}$ \\
\hline & F-Test & $*$ & $*$ & $*$ & $*$ & $*$ & $*$ & $*$ & $*$ \\
\hline & CV $(\%)$ & \multicolumn{4}{|c|}{3.81} & \multicolumn{4}{|c|}{3.29} \\
\hline
\end{tabular}

*At the $95 \%$ confidence level, the same characters in the column are not statistically significant differences., WAS $=$ number of weeks after storage

Table 4: The correlation between factors and responses

\begin{tabular}{rccccc}
\hline & SP & $\lambda \mathbf{I R}$ & Cycle & Seed vigour & Seed germination \\
\hline SP & 1.0000 & & & & \\
$\lambda \mathrm{IR}$ & 0.0123 & 1.0000 & & & \\
Cycle & 0.0112 & 0.0112 & 1.0000 & & \\
Seed vigour & 0.8443 & -0.0167 & -0.0071 & 1.00 & 1.0000 \\
\hline Seed germination & 0.8372 & -0.0246 & -0.0016 & 0.9941 & \\
\hline
\end{tabular}

\section{Conclusion}

Testing the effect of seed quality stimulation with infrared radiation with storage periods of 3 , 5,7 and 9 weeks, infrared wavelengths of 4.00, 3.75 and $3.52 \mu \mathrm{m}$, radiation cycles of 1,2 and 3 cycles, using a constant feed rate of $20 \mathrm{~kg} \cdot \mathrm{hr}^{-1}$ and a moisture content at $14 \% \mathrm{wb}$ on KDML 105 rice cultivar showed that:

1. Increasing the storage period affected the seed vigour and germination.

2. The wavelength of infrared radiation and the duty-cycle with which the paddy was stimulated had a significant correlation at $\mathrm{P} \leq 0.05$. When the infrared wavelength decreased, the surface temperature of the source increased, and when the number of stimulation cycles increased, this resulted in decreased seed quality.

3. The combination of a storage period of 5 weeks, infrared wavelength at $3.75 \mu \mathrm{m}$ and duty cycle of 2 resulted in a good performance response, in terms of both seed vigour and germination, showing increases from the reference value of $6.7 \%$ and $5.3 \%$, respectively (at $\mathrm{P} \leq 0.05$ ).

\section{Acknowledgements}

The authors are grateful to the Faculty of Engineering, Mahasarakham University and the Postharvest Technology and Agricultural Machinery Engineering Research Unit Faculty of Engineering, Mahasarakham University, for their valuable support for this research. 


\section{References}

AOSA, A. of official S. A. (1983). Seed Vigor Testing Hand book (32nd ed.). NE. U.S.A.: Association of Official Seed Analysts.

Chaiyachet, R. (2016). Study of Suitable Factors for Hang Rice Milling. UBU Engineering Journal, 2(9).

Cho, D. H., \& Lim, S. T. (2016). Germinated brownrice and its bio-functional compounds. Food Chemistry, 196, 259-271. https://doi. org/10.1016/j.foodchem.2015.09.025

Das, M., Gupta, S., Kapoor, V., Banerjee, R., \& Bal, S. (2008). Enzymatic polishing of rice A new processing technology. LebensmittelWissenschaft Und-Technologie.

Duangpatra, J. (1986). Seed testing and analysis. Kasetsart University. Bangkhen Campus, Bangkok (Thailand). Faculty of Agriculture. Department of Agronomy.

Fresco, L. (1947). Rice is life. Hospital Corps Quarterly, 20(2), 3-6. https://doi. org/10.1016/j.jfca.2004.09.006

Laohavanich, J. (2008). A study of paddy preparation by hydrothemal process using infrared radiation and tempering for increasing head rice yield.

Maisont, S., \& Narkrugsa, W. (2010). The Effect of Germination on GABA Content, Chemical Composition, Total Phenolics Content and Antioxidant Capacity of Thai Waxy Paddy Rice. In Nat. Sci.) (Vol. 44).

Moongngarm, A., \& Saetung, N. (2010). Comparison of chemical compositions and bioactive compounds of germinated rough rice and brown rice. Food Chemistry, 122(3), 782-788. https://doi.org/10.1016/j. foodchem.2010.03.053
National Bureau of Agricultural Commodity and Food Standards. (2012a). GERMINATED $B R O W N$ RICE (129th ed.). Retrieved from www.acfs.go.th

National Bureau of Agricultural Commodity and Food Standards. (2012b). GOOD MANUFACTURING PRACTICES FOR GERMINATED BROWN RICE.

Perry, D. A. (1981). Handbook of Vigour Test Methods. Zurich, Switzerland: International Seed Testing Association (ISTA).

Prakhethanang, D., Chiawchanwattana, C., Laohavanich, J., Khaengkhan, P., \& Yangyuen, S. (2019). The Influence of infrared radiation, Hot air and Tempering on Khao Dawk Mali 105 Rice Seedling Germination and Seedling Growth. Thai Society of Agricultural Engineering Journal, 1(26), 52-61.

Roohinejad, S., Omidizadeh, A., Mirhosseini, H., Saari, N., Mustafa, S., Meor Hussin, A. S., ... Abd Manap, M. Y. (2011). Effect of pre-germination time on amino acid profile and gamma amino butyric acid (GABA) contents in different varieties of Malaysian brown rice. International Journal of Food Properties, 14(6), 1386-1399. https://doi. org/10.1080/10942911003687207

Srisang, N., Varanyanond, W., Soponronnarit, S., \& Prachayawarakorn, S. (2011). Effects of heating media and operating conditions on drying kinetics and quality of germinated brown rice. Journal of Food Engineering, 107(3-4), 385-392. https:// doi.org/10.1016/j.jfoodeng.2011.06.030

Thongekkaew, J. (2015). A greatly useful of GABA for health. KKU Science Journal, 43(2), 205-211. 